\title{
Lullaby effect with mother's voice on respiratory rate and the speed of its return to the pre-suction state in intubated preterm infants, during tracheal tube suction Kerman, Afzali pour hospital 2016
}

\author{
Batool Pouraboli ${ }^{1}$, Masood Rayyani ${ }^{2}$, Mahlegha Dehghan Anari ${ }^{3}$, Fatemeh Hosseini ${ }^{4}$, Laleh Loghmani ${ }^{5}$
}

\begin{abstract}
Introduction \& Objective: Acceptance of newborns in the intensive care unit is regarded as one of the most important health care challenges due to the use of painful invasive procedures that are frequently performed on admitted infants. Today, the use of palliative non-pharmacological methods has been repeatedly emphasized in the literature. Therefore, the present study determine lullabies effect with mother's voice on heart rate in preterm infants during tracheal tube suction.

Materials and Methods: This cross over-interventional study was conducted on 40 preterm infants during a five-month period in 2016, who were admitted in NICU in the Afzalipour Hospital affiliated to Kerman University of Medical Sciences. After convenience random sampling, infants were divided into two groups of Routine care / Lullaby and Lullaby / Routine care. At the intervention time, mother's lullaby was played for the infants from the 5 minutes before suction until 10 minutes later. Physiological responses of infants, including respiratory rate, were measured one minute before endotracheal suctioning as baseline information and five minutes to thirty minutes continued after suction. Finally, statistical analysis of data was performed by SPSS software version 23.

Results: The results showed that mother's lullaby in intubated preterm infants who were suctioned, not only was effective on fast return of breathing changes after the suction, but also it reduced respiratory rate $(0.007 \mathrm{p})$, which can also indicate the stress reduction in infants.

Conclusion: The participation and presence of mothers in taking care of preterm infants not only improves the quality of nursing care, but can also has a significant effect on their physiological responses.
\end{abstract}

Keywords: preterm infant, respiratory, mother's lullabies, suction

\section{INTRODUCTION}

Every society depends on the health of its people for progress, and the health of infants and children as the country's prospective developers is of particular importance. Low birth weight newborn (L.B.W) and preterm infants are the group at risk in society and experience many physical and psychological problems in relation to normal babies (1).

Despite progress in prenatal care and the improvement of health indicators, still $5 \%$ of all pregnancies are preterm, and preterm infant is still the leading cause of infant mortality in developed countries (2).

According to the WHO definition, babies born before the 37th week of pregnancy from the first day of the last menstrual period are preterm, and babies born before the 32nd week of pregnancy are considered as very preterm infants (3). Since 1990, the birth rate of preterm infants has risen by almost $20 \%$. Data from the International Center for

\footnotetext{
PhD, Assistant Professor of nursing, School of Nursing and Midwifery. Department of pediatric and neonatal nursing, Tehran University of Medical Sciences, Tehran, Iran.

2 PhD, Assistant Professor of nursing, School of Nursing and Midwifery. Department of public health, Kerman University of Medical Sciences, Kerman, Iran.

3 PhD, Assistant Professor of nursing, School of Nursing and Midwifery. Department of Critical care, Kerman University of Medical Sciences, Kerman, Iran.

${ }^{4}$ MSC in NICU Nursing Nursing and Midwifery Kerman School of Razi, University of Medical Sciences, Kerman, Iran.

5 Assistant Professor, School of Nursing and Midwifery, Bam University of Medical Sciences, Bam, Iran.
}

Correspondence: Laleh Loghmani

Assistant Professor, School of Nursing and Midwifery, Bam University of Medical Sciences, Bam, Iran.

E-mail:mlloghmani1384@yahoo.com

Received: 9 Mar 2018, Accepted: 18 May 2018

(C) 2019 by the authors; licensee Modestum Ltd., UK. This article is an open access article distributed under the terms and conditions of the Creative Commons Attribution License (http://creativecommons.org/licenses/by/4.0/). 
Health Statistics at Alabama at Birmingham show that the preterm birth was $12.8 \%$ of babies born alive in 2006 (4). Iran is also among the areas with high prevalence of preterm delivery. According to the latest statistics published by the Ministry of Health and Medical Education in 2003, 13.5\% of Iranian babies were born preterm (5). In the study of Mardanian in 2011 in Isfahan, the proportion of preterm infants to neonates hospitalized in NICU was 78\%. Each year, approximately $10-15 \%$ of newborns are admitted to NICU, and these admissions are usually unpredictable. (6).

With the advancement in NICU, mortality has been significantly reduced, but a high prevalence of behavioral and cognitive problems in more than $50 \%$ of preterm infants observed in toddler ages and childhood [7]. The preterm baby is born when the brain growth process such as the natural myelination of neurons as well neurons transferring from germinal to thalamus and cortex and synaptogenesis is completed. This evolutionary process of the brain at an early ages of pregnancy leads to the vulnerability feature of brain in front of disorder (8).

Respiratory diseases are one of the important causes of hospitalization preterm infants in NICU (9). According to statistics, hyaline membrane disease (HMD) (45\%), transient tachypnea of the newborn (TIN) (20.2\%) and pneumonia with $9 \%$ are the most common causes and aspiration, diaphragmatic hernia, lung and trachea fistula, pulmonary hypoplasia, pneumothorax and choanal atresia are the other causes lead to respiratory distress in newborns and the most common causes of infant mortality are HMD (60\%) (10).

Today, in intensive care units for some of these babies, mechanical ventilation is used for many physiological and clinical reasons (11). The overall complication rate of mechanical ventilation in newborns is about $31.9 \%$, which mainly includes compressive trauma and air leak syndrome and traumatic injury to large airways and complications of tracheal intubation (12). Since these patients have endotracheal tubes, tracheal tube suction should be done as needed, in order to enhance oxygenation and keep the airways open. Although suction is a necessity for intubated patients, but its application can also have negative effects. Including changes in vital signs of the newborns as a disorder (increase or decrease) in respiration and heart rate, decrease in the saturation of oxygen (due to manipulation during ventilation and loss of chest pressure), pneumonia, fluctuation in blood pressure and intracranial pressure, airway trauma, sepsis and extubation of the tracheal tube (11).

The tolerance of injuries caused by premature birth and subsequently admission to NICU (13) increases the energy consumption and need for oxygen in preterm infants, which can impede the growth and developmental capacity of the baby (14). Research in recent years has proven that, infants, especially preterm infants, are more susceptible to stimuli than older children are and give a physiological, behavioral, hormone and severe metabolic response to stimuli, which can have short and long-term destructive effects (15). NICU cannot provide a satisfactory type of sensory stimulation to the preterm infants in the critical period of nerve growth (16).

Desirable auditory stimuli have an effect on the oxygenation of the preterm infants by regulating of respiration and heart rate, and increased saturation of oxygen in the blood. The study of the effect of music in animals showed that music with rhythm harmonizes the activity of neurons, this can regulate respiratory patterns, heart rate and, as a result, oxygenation (especially when the baby is stimulated undergoing aggressive therapies such as suction and physiological responses change) (17). Changing caregiving practices in NICU to reduce the complications of the treatment remains as an important challenge for babies in this segment. In recent years, much attention has been paid to providing evolutionary supportive care (such as kangaroo mother care (KMC), massage, swaddling, music, etc.) as a way of adjusting the stress experienced in vulnerable neonates in NICU. Many studies have suggested that providing evolutionary care during procedures may be useful to keep the baby out of stress-induced treatment and for managing non-complicated behavioral reactions (18). Several studies have shown that fetus respond to rhythmic and musical performance, and a term baby can recognize his mother's voice, recognize the woman's voice from the man and understand the stories and songs in the local language during the last trimester of pregnancy (19) .

The aim of this study was to determine the effect of mother's lullabies on heart rate during tracheal tube suction in preterm infants.

\section{METHODS}

The present study was a cross over-interventional study that was carried out during April-August 2016 in NICU of Afzalipour Hospital in Kerman. 40 preterm infants with a gestational age of 28 to 36 weeks were selected by simple randomization (neonates selected as sample who admitted in the care unit, by having the conditions for entering the study). Using randomization they divided into two groups: Routine care / Lullaby and Lullaby / Routine care. The results of Karimi et al. (2012) and the following formula was used to estimate the sample size. 
- Mean and standard deviation of oxygen saturation in the first group: $94.93 \pm 1.08$

- Mean and standard deviation of oxygen saturation in the second group: $93.57 \pm 0.77$

Therefore, the sample size was determined 13 individuals in each group using upper paper and according to the sample size formula. According to the probability of falling of samples, 20 samples were considered in each group (20).

Entry requirements were preterm neonates with a gestational age of 28 to 36 weeks, with respiratory distress syndrome (no congenital anomalies or severe heart disease). Receiving auxiliary ventilation through the tracheal tube and tracheal suction with 4 hours interval at least. Receiving oxygen by fio 2 is less than or equal to $40 \%$, scores less than 30 based on the system for measuring interventional therapies in infants and not having hearing impairment (21).

Exit conditions include parental withdrawal at any stage of the project. In cases when the interval between two suctioning is less than 4 hours. Any kind of difficulty in recording heart rate (crying or restlessness), severe reactions or abnormal responses of the newborn to acoustic stimuli or the need for any medical or nursing intervention in a sample that requires anticonvulsant medication or sedation during the intervention (22).

Neonates were examined three days after birth, because in the first three days of birth, the possibility of fluid in the ear and hearing impairment in the preterm infant are given, in addition the baby has more physiological stability after three days.

Infants in the lullabies level received it from the 5 minutes before suction until 10 minutes later, in addition to routine care. The used lullaby was recorded one with the voice of the mother through the MP3 Player

(30K mp3 model, Ce-FCCE, Transcend) and headphones of 45-50dB. The intensity of the sound in the NICU environment was measured by a professional health specialist using the SUANTEK SVAN971 sound level meter in 60-65 $\mathrm{dB}$ before the intervention, and then the intensity was announced 45-50dB for lullabies through headphones.

Audiologists using otoacoustic emission test (OAE) with the OTOREAD audiometer made in Denmark evaluated the infants who entered the study, and those who had hearing impairment were removed from the group.

Data collection tools included demographic characteristics form, physiological response record form, and the form of neonatal therapeutic intervention scoring system. Demographic characteristics including gender variables, gestational age, weight, first and fifth minutes of the Apgar score, the newborn score based on the NTISS (Neonatal Therapeutic Intervention Scoring System), age at the study period, mother's age and type of delivery; this data has been completed using information from the medical record of the newborn.

A physiological response record form included heart rate data, in which a table was prepared and the researcher observed and recorded data through monitoring at each stage (Lullaby and Routine care) one minute before suction and every 5 minutes after suction for up to 30 minutes.

Content validity method was used to determine the validity of the demographic profile form and the physiological response record form. The validity of the cardiopulmonary monitoring devices, digital scales, suction and chronometer was announced before the study by medical engineering, and this evaluation was repeated every fifteen days.

Each newborn was selected by available allocation method and using randomization, they divided into two groups: Routine care / Lullaby and Lullaby / Routine care to determine whether to receive routine care first or lullaby. If the newborn was selected in the Routine care / Lullaby group, they first received routine care and then interventions after 4 hours (washout period), and if they were in Lullaby / Routine care group, they first intervened and then received routine care after 4 hours.

The electrodes for recording heart rate were fixed on the anterior and posterior surfaces of the leg with anti-allergenic adhesives, so that they can be prevented from relocation during heart rate recording. In the routine care phase, the headphones putted on silent mode on the baby's ear. Researcher and authorized nurse reported respiratory rates of infants for one minute before suction as basal information and every 5 minutes after suction for up to 30 minutes while taking the usual care. In thirty minutes after suction, avoided from interventions, which led to stimulation or manipulation and pain in infants. Newborns who needed nursing or medical care at this time, or occurred impairments in their data recordings due to restless were excluded. In the lullaby phase, mother's voice was played through headphones in $45-\mathrm{dB}$ for the baby 5 minutes before suction up to 10 minutes after suction, data was recorded in the same way. Statistical analysis was performed using SPSS version 23 software. Descriptive statistics (frequency, percentage, mean and standard deviation), paired T-test methods and repeated measurements (or their nonparametric equivalents; Mann-Whitney $U$ and Friedman) were used for data analysis. 
Table 1: Demographic characteristics of research units in two groups: Lullaby / Routine and Routine care / Lullaby (quantitative variables)

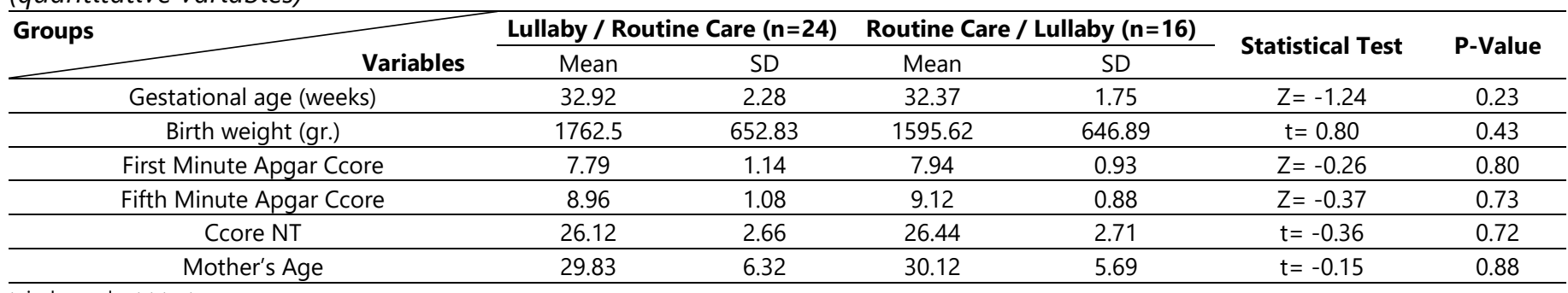

$\mathrm{t}$ independent $\mathrm{t}$ test

Z: Mann-Whitney U test

Table 2: Demographic characteristics of research units in two groups: Lullaby / Routine and Routine care / Lullaby (qualitative variables)

\begin{tabular}{|c|c|c|c|c|c|c|}
\hline \multirow{2}{*}{$\begin{array}{ll}\text { Groups } & \text { Variables } \\
\end{array}$} & \multicolumn{2}{|c|}{ Lullaby / Routine care } & \multicolumn{2}{|c|}{ Routine care / Lullaby } & \multirow{2}{*}{ Statistical Test } & \multirow{2}{*}{ P-value } \\
\hline & Frequency & $\%$ & Frequency & $\%$ & & \\
\hline \multicolumn{5}{|l|}{ Gender } & \multirow{3}{*}{$\chi^{2}=7.42$} & \multirow{3}{*}{0.006} \\
\hline Male & 9 & 37.5 & 13 & 18.8 & & \\
\hline Female & 15 & 62.5 & 3 & 81.3 & & \\
\hline \multicolumn{5}{|l|}{ Type of Delivery } & \multirow{3}{*}{$\chi^{2}=0.29$} & \multirow{3}{*}{0.59} \\
\hline Normal & 3 & 12.5 & 3 & 18.8 & & \\
\hline Cesarean & 21 & 87.5 & 12 & 81.3 & & \\
\hline \multicolumn{5}{|l|}{ The Cause of Preterm Delivery } & \multirow{5}{*}{$\chi^{2}=1.69$} & \multirow{5}{*}{0.64} \\
\hline Gestational Diabetes & 4 & 16.7 & 5 & 31.3 & & \\
\hline Increase in Blood Pressure & 3 & 12.5 & 1 & 6.3 & & \\
\hline Other Cases & 5 & 20.8 & 4 & 25 & & \\
\hline Unknown & 12 & 50 & 6 & 37.5 & & \\
\hline
\end{tabular}

Table 3: Comparison of the mean respiratory rate before the start of the study in two groups: Lullaby / Routine care and Routine care / Lullaby

\begin{tabular}{|c|c|c|c|c|c|c|c|}
\hline \multirow{2}{*}{ Groups } & \multirow[b]{2}{*}{ Variables } & \multicolumn{2}{|c|}{ Lullaby / Routine Care } & \multicolumn{2}{|c|}{ Routine care / Lullaby } & \multirow{2}{*}{ Statistical Test } & \multirow{2}{*}{ P-Value } \\
\hline & & Mean & SD & Mean & SD & & \\
\hline Heart Rate & & 149.08 & 10.00 & 139.88 & 26.87 & $Z=0.28$ & 0.29 \\
\hline
\end{tabular}

Z: Mann-Whitney U test

\section{FINDINGS}

In this study, 40 preterm infants selected by available allocation method and participated in the study. They divided into two groups: Lullaby / Routine care $(n=24)$ and Routine care / Lullaby $(n=16)$ using randomization. The collected data in Tables 1 and 2 refer to the frequency distribution of the research units according to the demographic variables in the two groups.

According to Table 1 there was no significant difference between Routine care / Lullaby and Lullaby / Routine care groups at the beginning of the study, in terms of underlying variables such as gestational age, first and fifth minute Apgar score, birth weight, NTISS score and mother's age. The two groups were identical in terms of these variables. It should be noted that the age of all samples was three days while studying.

According to Table 2, there was a significant difference between the Lullaby / Routine care and Routine care / Lullaby groups in terms of gender variable in the beginning of the study. There was no significant difference between the two groups in terms of type of delivery and the cause of early delivery, and the two groups were similar in terms of these variables.

According to Table 3, there was no significant difference between the mean of heart rate in the two groups of Lullaby / Routine care and Routine care / Lullaby before the beginning of the study, and the two groups were similar in terms of these variables. 


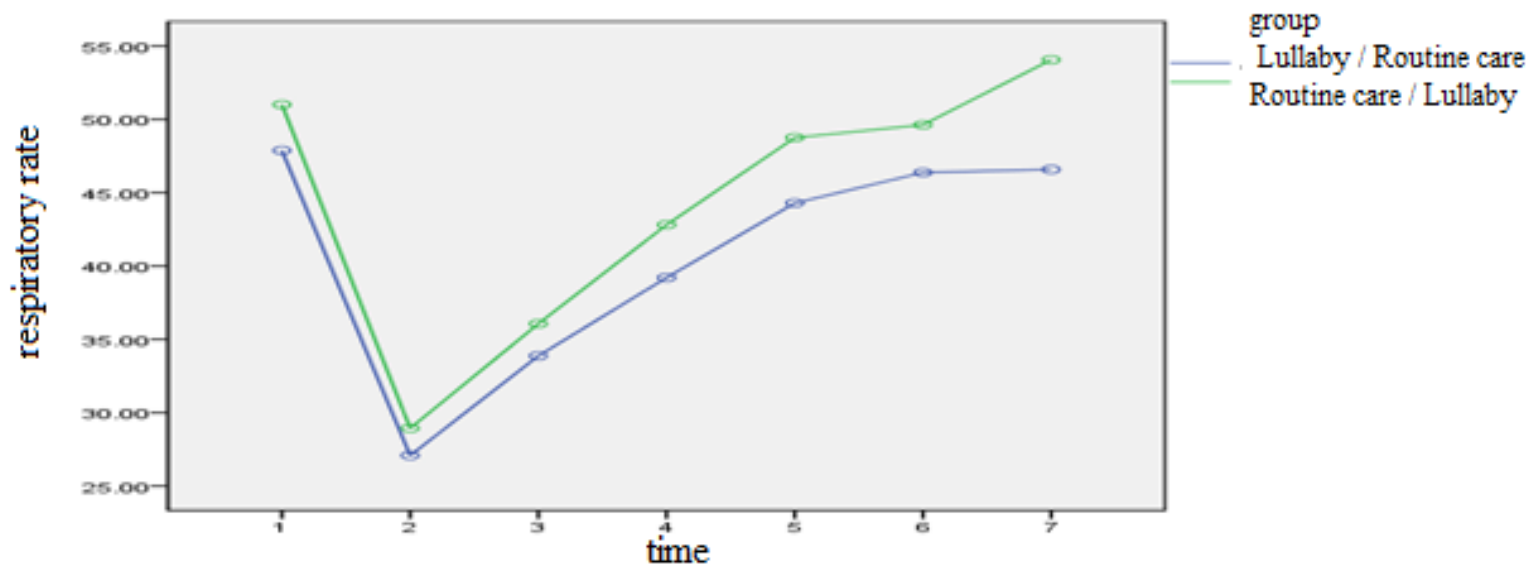

Figure 1: Respiration average in the first stage in Lullaby / Routine care group and Routine care / Lullaby at different times

Table 4: Comparison of the respiration average in the first stage between the two groups of Lullaby / Routine care and Routine care / Lullaby at different times

\begin{tabular}{|c|c|c|c|c|c|c|c|}
\hline \multirow[t]{2}{*}{ Group } & \multirow[b]{2}{*}{ Time } & \multicolumn{2}{|c|}{ Lullaby / Routine care } & \multicolumn{2}{|c|}{ Routine care / Lullaby } & \multirow{2}{*}{ Statistical Test } & \multirow{2}{*}{ P-Value } \\
\hline & & Mean & SD & Mean & SD & & \\
\hline 1 Min after Suction & & 47.88 & 12.13 & 51.00 & 18.32 & $Z=0.65$ & 0.65 \\
\hline 5 Min after Suction & & 27.08 & 7.82 & 28.94 & 9.25 & $Z=-0.36$ & 0.73 \\
\hline 10 Min after Suction & & 33.88 & 7.92 & 36.06 & 11.97 & $Z=-0.47$ & 0.65 \\
\hline 15 Min after Suction & & 38.21 & 8.24 & 42.81 & 15.65 & $Z=-0.61$ & 0.56 \\
\hline 20 Min after Suction & & 44.29 & 7.58 & 48.75 & 14.17 & $Z=-1.41$ & 0.16 \\
\hline 25 Min after Suction & & 43.38 & 8,30 & 49.62 & 12.54 & $Z=-1.50$ & 0,14 \\
\hline 30 Min after Suction & & 46.58 & 8.42 & 54.06 & 8.73 & $Z=-2.65$ & 0.007 \\
\hline Statistical Test & & \multicolumn{2}{|c|}{$\chi^{2}=84.36$} & \multicolumn{2}{|c|}{$\chi^{2}=60.06$} & & \\
\hline $\mathrm{P}$ value & & \multicolumn{2}{|c|}{$P=0.000$} & \multicolumn{2}{|c|}{$P=0.000$} & & \\
\hline
\end{tabular}

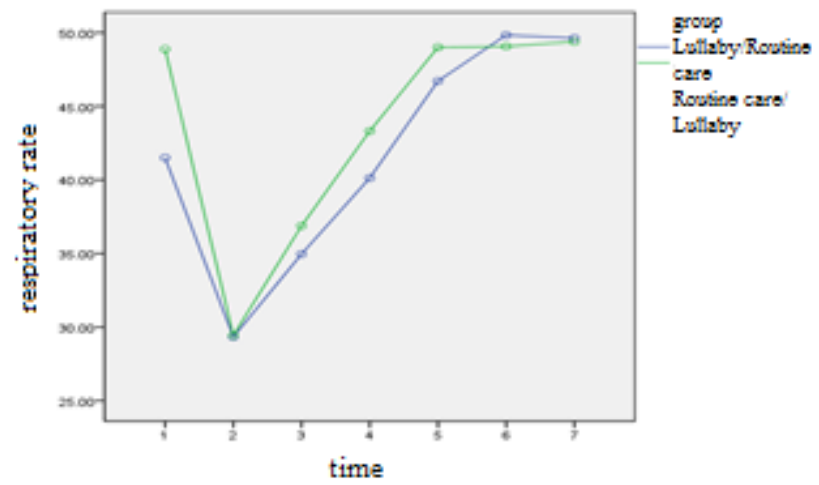

Figure 2: Comparison of the respiration mean in the second stage between the two groups of Lullaby / Routine care group and Routine care / Lullaby at different times

In order to compare the mean of respiratory rate in the first stage, in 7 intervals (one minute before suction, 5 minutes, 10 minutes, 15 minutes, 20 minutes, 25 minutes and 30 minutes after suction) Friedman test was used in each group due to non-compliance of the normal distribution. Mean respiration at different times in both groups was significantly different. Pairwise comparison of respiration mean in Lullaby / Routine care group showed that respiration rate significantly decreased $(P<0.05)$ at $5,10,15$, and 20 minutes after suction respectively $43.44 \%, 29.24 \%, 11.18 \%$ and $7.50 \%$, but there was no significant difference between the mean of respiratory rate before suction with the respiratory rate in 25 and 30 minutes after suction. In other words at the first stage, in the Lullaby / Routine care group, the respiratory rate of infants in 20 min after suctioning was significantly less than pre-suctioning. Pairwise comparison of respiration mean in the Routine care / Lullaby group showed that respiration rate was significantly decreased $(P<0.05)$ at 5 and 10 minutes after suction, respectively, $43.25 \%$ and $29.29 \%$ but there was no significant difference between the respiratory rate mean before suction with respiratory rate 15, 20, 25 and 30 minutes after suction. In other words at the first stage, in the Routine care / Lullaby group, the respiratory rate of infants in 5 min after suctioning was significantly less than pre-suctioning. 
Table 5: Compare the respiratory rate mean in different times between two groups

\begin{tabular}{|c|c|c|c|c|c|c|c|}
\hline \multirow[t]{2}{*}{ Group } & \multirow{2}{*}{ Time } & \multicolumn{2}{|c|}{ Lullaby / Routine Care } & \multicolumn{2}{|c|}{ Routine Care / Lullaby } & \multirow{2}{*}{ Statistical Test } & \multirow{2}{*}{ P-Value } \\
\hline & & Mean & SD & Mean & SD & & \\
\hline One Min before Suction & & 41.5 & 13.77 & 48.88 & 15.39 & $Z=-1.44$ & 0.16 \\
\hline 5 Min after Suction & & 29.33 & 9.77 & 29.44 & 6.89 & $Z=-0.32$ & 0.75 \\
\hline 10 Min after Suction & & 34.96 & 6.78 & 36.88 & 9,29 & $Z=-0.60$ & 0.56 \\
\hline 15 Min after Suction & & 40.12 & 9.98 & 43.31 & 10.59 & $Z=-0.78$ & 0.45 \\
\hline 20 Min after Suction & & 46.71 & 8.96 & 49.0 & 9.05 & $Z=-0.72$ & 0.49 \\
\hline 25 Min after Suction & & 49.83 & 8.11 & 49.06 & 9.77 & $Z=-0.29$ & 0.77 \\
\hline 30 Min after Suction & & 49.62 & 8.42 & 49.38 & 9.92 & $Z=-0.28$ & 0.80 \\
\hline Statistical Test & & & & & & & \\
\hline
\end{tabular}

In addition, the Mann-Whitney test was used to compare the respiratory rate mean in different times between the two groups. The results of data analysis showed that there was a significant difference in respiratory rate at 30 minutes after suction between the two groups and the respiratory rate in the routine / routine care group was lower than the Routine care / Lullaby. There was no significant difference in the mean of respiration in other times between the two groups.

In order to compare the mean of respiratory rate in the second stage, in 7 intervals (before suction, immediately, 5 minutes, 10 minutes, 15 minutes, 20 minutes, 25 minutes after suction) Friedman test was used in each group due to non-compliance of the normal distribution.

Mean respiration at different times in both groups was significantly different. Pairwise comparison of respiration mean in Routine care / Lullaby group showed that respiration rate significantly decreased $(P<0.05)$ at 5,10 minutes after suction but there was no significant difference between the mean of respiratory rate before suction with the respiratory rate in 15, 20, 25 and 30 minutes after suction. In other words at the second stage, in the Routine care / Lullaby group, the respiratory rate of infants in $10 \mathrm{~min}$ after suctioning was significantly less than pre-suctioning. Pairwise comparison of respiration mean in the Lullaby / Routine care group showed that respiration rate was significantly decreased $(P<0.05)$ at 5 minutes after suction than before suction. In other words respiratory rate mean in 25 and 30 min after suction significantly increased than pre-suctioning.

In addition, the Mann-Whitney test was used to compare the respiratory rate mean in different times between the two groups. The results of data analysis showed that there was no significant difference in respiratory rate between the two groups in different times.

\section{DISCUSSION}

Suction and serum therapy control in preterm infants are two invasive interventions and based on Appletan findings allocated $48 \%$ of the 24 hours in a day to themselves, and in $57 \%$ of the cases completed without pain-relieving interventions (23).

In their study, Asqari et al. (2013) compared the effect of open and closed chip suction on changes in vital signs of neonates under mechanical ventilation, and concluded that closed suction in comparison with open suction induced fewer changes in hemodynamic status of newborns. However, in both cases, before the suction, the oxygen levels of the blood are reduced and respiration and heart rate increased due to the accumulation of discharge in the airways, and after suction, the heart rate is increased, but respiration and oxygen saturation decreases (24).

Andréa Lopes et al. (2011) also found that after suction, respiratory rates decreased, and heart rate increased and blood oxygen saturation was more stable (25).

The results of this study showed that mother's lullabies is effective on the heart rate of the intubated preterm newborns who receive suction. Mother's Lullabies are unproblematic, easy, affordable, and accessible interventions along with compassion, cooperation, and mother's consent. In this study, we tried to control, compare and homogenize the confounding factors such as touch, nutrition, hypothermia, suction (how to do it and its duration), additional sounds and neonatal factors affecting the number of heart rate in two groups in terms of different variables. The auditory system responds to the acoustic actuators by changing in respiration rate, arterial oxygen concentration and heart rate, so it can be said that mother's lullabies without communication with these variables, causes more pronounced changes in heart rate, stability and faster return to normal state.

Considering these changes, Maroufi and colleagues (2014), in the study about effect of melody on the physiological responses of pain caused by piercing the heel in neonates, concluded that heart rate and respiratory rate between the 
intervention and control groups were significantly different. However, there is no significant difference between the two groups in term of oxygen saturation. In this study, 50 newborns with a gestational age of 34 weeks who did not receive oxygen and other painful procedures during the hospitalization were selected by simple sampling from Alzahra hospital in Isfahan for 5 months. A melody called golden sleep, performed on the piano with $65 \mathrm{~dB}$ one meter nearby baby in the intervention group. The melody started from three minutes before the piercing and lasted for three minutes. The researcher recorded and compared together the physiological responses of the infant at the same time by monitoring (26).

Keith (2009) and his colleagues in a similar study, selected 24 newborns with a gestational age of 32 to 40 weeks, while these babies were non oral (NPO) and did not need interpretation support, and they did not respond to nursing interventions after 5 minutes of restlessness and crying. Lullaby was played below $70 \mathrm{~dB}$. Heart rate, respiratory rate, arterial oxygen content, crying length and crying number were recorded during the day. The result showed that the length and number of crying, as well as the heart rate and respiration decreased and blood oxygen levels increased when the music was played. There were no statistical differences in the days when the music was not played. These differences indicate that music can be effective when the baby is restless in a natural state and does not respond to nursing interventions to calm down (27). This study was also consistent with the results of upper study, and mother's lullabies were effective in reducing the respiratory rate in preterm infants and faster returning to normal state.

\section{CONCLUSION}

The results showed that in the first stage of the two groups, according to the results, there was a significant difference in respiration rate in 30 minutes after suction between the two groups and respiration rate in the Lullaby / Routine care group was lower than Routine care / Lullaby group. But in the second stage of the two groups the respiratory rate of the infants was significantly less than before the suction for 10 minutes in Routine care / Lullaby group, but there was no difference between respiratory rate before the suction with the respiratory rate of 15,20,25 and 30 minutes after suction. Pairwise comparison of respiration mean in Lullaby / Routine care group showed that respiration rate significantly decreased $(P<0.05)$ at 5 minutes after suction. On the other hand, mean of respiratory rate in 25 and 30 minutes was significantly increased compared to before suction $(P<0.05)$. Therefore, mother's lullabies are effective in respiratory rate after suction and reducing the respiratory rate in comparison with the time, when patient does not receive mother's lullabies.

The results of this study can be used in clinical services to help stabilize vital signs in intubated preterm infants, which can also be effective in reducing the complications of suction and the resulted stress and improve relationships between parents and children. It is suggested that in future studies, should be used the effect of mother's lullabies on physiological responses during other aggressive interventions such as drainage of cerebrospinal fluid, insertion of a catheter, replacement of blood, etc.

\section{ACKNOWLEDGEMENTS}

This article is the result of research in the form of a dissertation of the Master's degree in neonatal intensive care nursing, approved by the number of (IR.KMU.REC.2016.08) in vice-presidency of research in Kerman University of Medical Sciences and costs has been provided. In this way, I would like to thank and appreciate the vice-chancellor of the research and the honorable council. The researcher is obligated to thank the honorable NICU expert in charge in Afzalipour Kerman Hospital, as well as the head nurse and the respected and hardworking staff of this section who also provided us with the help.

\section{REFERENCES}

1. S DR, M L. Information needs of parents of children admitted to a neonatal intensive care unit: a review of the literature (1990-2008). Patient education and counseling. 2009:76(2):159-73. https://doi.org/10.1016/j.pec.2009.01.014

2. Beigi A, Taheri N, Norouzi HR. The prevalence of very preterm deliveries, risk factors, and neonatal complications in Arash women hospital: a brief report. Tehran University Medical Journal. 2013;71(3):194-8.

3. Nelson N. Neonatal. Martyr Beheshti University of Medical Sciences. 2011.

4. Wood A. Effects of music therapy on preterm infants in the neonatal intensive care unit: The University of Alabama at Birmingham; 2008. 
5. Keshavars $M$, Eskandari $N$, Jahdi F, Ahaieri H, Hoseini F, Kalani M. The effect of holly Quran recitation on physiological responses of premature infant. Journal of Semnan University of Medical Sciences. 2010:11(3):16977.

6. Kobra O, Foroozan A-S. The conformity rate of nursing care during newborn admission with the standards in Neonatal Intensive Care Unit Medical - Surgical Nursing Journal. 2015;4(2):24-32.

7. Delobel-Ayoub M, Arnaud C, White-Koning M, Casper C, Pierrat V, Garel M, et al. Behavioral problems and cognitive performance at 5 years of age after very preterm birth: the EPIPAGE Study. Pediatrics. 2009;123(6:92148:(5).

8. Verney C, Pogledic I, Biran V, Adle-Biassette H, Fallet-Bianco C, Gressens P. Microglial reaction in axonal crossroads is a hallmark of noncystic periventricular white matter injury in very preterm infants. Journal of $\begin{array}{llll}\text { Neuropathology } \& \quad \text { Experimental } & \text { Neurology. }\end{array}$ https://doi.org/10.1097/NEN.0b013e3182496429

9. Holmstrom S, Phibbs C. Regionalization and mortality in neonatal intensive care. Pediatr Clin North Am. 2009 Jun: 56(3):617-30. https://doi.org/10.1016/j.pcl.2009.04.006

10. Musa RA, Tahereh $M$, inventors the prevalence of the most important causes of respiratory distress in newborns admitted to NICU2012.

11. Paula L, Ceccon M. Randomized, comparative analysis between two tracheal suction systems in neonates. Rev Assoc Med Bras. 2010;56(4):434-9. https://doi.org/10.1590/S0104-42302010000400016

12. Miller JD, Carlo WA. Pulmonary complications of mechanical ventilation in neonates. Clinics in perinatology. 2008;35(1):273-81. https://doi.org/10.1016/j.clp.2007.11.004

13. Caskey M, Stephens B, Tucker R, Vohr B. Importance of parent talk on the development of preterm infant vocalizations. Pediatrics. 2011;128(5):910-6. https://doi.org/10.1542/peds.2011-0609

14. Porges SW, Furman SA. The early development of the autonomic nervous system provides a neural platform for social behaviour: a polyvagal perspective. Infant and Child Development. 2011;20(1):106-18. https://doi.org/10.1002/icd.688

15. Lago P, Garetti E, Merazzi D, Pieragostini L, Ancora G, Pirelli A, et al. Guidelines for procedural pain in the newborn. Acta paediatrica (Oslo, Norway: 1992). 2009;98(6):932-9. https://doi.org/10.1111/j.16512227.2009.01291.x

16. P.F A, E wL, L J. Influence of gestational age and postnatal age on speech sound processing in nicu infants. NIH Public Access. 2012;49(5):720-31.

17. R A. Lullaby effect on blood oxygen saturation in preterm infants. Journal of Birjand University of Medical Sciences. 2008;15(4).

18. Cone S. Endotracheal suctioning in preterm infants using four-handed versus routine care. NIH Public Access. 2013 42-92-104:(1).

19. A S, Peczeniuk-Hoffman. Interventions and techniques in current practice and a survey of experience and designation implications. Western Michigan University Scholar Works at WMU. 12-1-2012:93.

20. Karimi R. The effect of music therapy on physiological responses of blood pain in premature infants. Faculty of Nursing and Midwifery, Tehran University of Medical Sciences (life). 2012;18(2):76-86.

21. Chou L. Effects of Music Therapy on Oxygen Saturation in Premature Infants Receiving Endotracheal Suctioning. Nursing Research. 2003;11(3):205-15. https://doi.org/10.1097/01.JNR.0000347637.02971.ec

22. Taheri l, sobhanian $\mathrm{s}$, mosalanejad $\mathrm{z}$, hojat $\mathrm{m}$. Comparison the effect of Quran and lullaby on heart rate changes of hospitalized neonates in Neonatal Intensive Care Unit. 2. 2015;4(2):16-0.

23. Cevasco A. The effects of mothers' singing on full-term and preterm infants and maternal emotional responses. Music Ther. 2008;45(3):273-306. https://doi.org/10.1093/jmt/45.3.273

24. Asgari N, Taheri $P$, Golchin $M$. The effect of open and closed endotracheal tube suctioning system on cardiorespiratory parameters of infants undergoing mechanical ventilation. Journal of development research in nursing midwifery 2013:14-20.

25. Lopes Barbosa A. Endotracheal and upper airways suctioning: changes in newborns' physiological parameters. Original Article. 2011;19(6):1990-76. https://doi.org/10.1590/S0104-11692011000600013 
26. Marofi M, Nikobakht F, Badiee Z, Golchin M. The effect of melody on the physiological responses of heel sticks pain in neonates. Iranian journal of nursing and midwifery research. 2015;20(3):405-8.

27. DR K, K R, BS W. The effects of music listening on inconsolable crying in premature infants. Music Ther [PubMed: 19757875]. 2009;49:191-203.

$\diamond \diamond \diamond \diamond \diamond \diamond \diamond$

http://www.ejgm.co.uk 